Original Research Paper

\title{
The Benefits of Bezier, B-Spline Algorithm in the Industry World
}

\author{
Djunaidy Santoso \\ Magister of Computer Science, Bina Nusantara University, Jl. K.H. Syahdan No. 9, Kemanggisan, Palmerah, Jakarta \\ 11480, Indonesia
}

Article history

Received: 20-11-2013

Revised: 09-12-2013

Accepted: 09-12-2014

\begin{abstract}
Computer Graphics is a science which is widely used in all fields, especially in the fied of Industries, companies, banking and even hospitals. In the aviation industries, marines and automotves, computer graphics with its latest technologies, can be used to solve graphical or imaging problems. Wherever images is involved, for eaxmple for patients' need in the hospitals, shipping engineers/designers or decision makers in an industry, the images can be analyzed in order to produce a better image in which the accuracy being continuously being researched. (CAD or CAM) (Newman and Sproull, 1981; Date, 1990; Pressman, 2001). The objective of this research is to combine the algorithms in order to create an image which is accurate and can be used by decision makers accordingly. This is performed by associating the Hermite, Bezier, B-Spline algorithms to its harmonic functions such that the resulting curves/images becomes better and more well-formed. This research will produce a picture/image/shape that will serve the needs of the designers. (Newman and Sproull, 1981; Connolly and Begg, 2002; Ramez et al., 2000; Date, 1990; Pressman, 2001).
\end{abstract}

Keywords: Computer Graphics, Algorithms, Blending Function Relationships/Harmony, Well-Shaped Curve, Pictures, Image, CAD/CAM

\section{Introduction}

With more algorithms in the field of computer graphics, more time will be required to decide and determine the appropriate algorithms to use.

Therefore a research is necessary to determine the best algorithms to be used when dealing with curves and need to be according to the users' needs.

Problem Identification: From the industry's or other institution's statistical data (Giloi, 1999), many curves are generated however the curves are not smooth, such that it can not be used $b$ the indistry/organization (Newman and Sproull, 1981; Ramez et al., 2000; Date, 1990; Pressman, 2001).

\section{Specific Objectives}

This research is developed with the objectives and benefits as follows:

- To develop a curve/image for automotive industries (machinery), ships and aeroplanes and building designs

- To analyze and develop well-shaped curves or to develop a smooth curve from images obtained from Sattelites (GIS)
- To be used in the fields of statistics, hospitals and other industries

\section{Advanced Research Urgency}

Image/picture/shape designers nowadays are being preoccupied with smooth images in the industries, such that it is necessary to have a special method to handle the images, such as a software package to produce the images/pictures/shapes in the form of the users' requirement (for example AutoCad, Microsoft word, Paintbrush, 3D Max) (Newman and Sproull, 1981; Pressman, 2001). In this case, for this research, it is necessary to have the accuracy, precision and the smoothness of the curves/images/pictures/shapes which is according to the user's requirements (Newman and Sproull, 1981; Connolly and Begg, 2002; Ramez et al., 2000; Date, 1990; Pressman, 2001). Therefore this research is very important.

\section{Materials and Methods}

As described earlier, this research will be conducted using the following methodology. 
Literature studies, searching data and information on the internet. This is conducted in order to get the latest and most updated information regarding the methods and model in this research and also to study the existing and currently used methods.

The Fig. 1 above to stream Thinking Research, with this we can work (Newman and Sproull, 1981; David and Adams, 1998; Giloi, 1999; Connolly and Begg, 2002; Ramez et al., 2000; Date, 1990; Pressman, 2001).

Data analysis is performed to analyze all the collected data (Giloi, 1999).

System development is performed t obtain the user's requirements and the system requirements (Newman and Sproull, 1981; Connolly and Begg, 2002; Ramez et al., 2000; Date, 1990; Pressman, 2001).

System implmentation is to create and develop a model/simulation such that a software/application is developed by writing the program (Newman and Sproull, 1981; Ramez et al., 2000; Date, 1990; Pressman, 2001).

Testing dan evaluating the system (Ramez et al., 2000; Pressman, 2001). Testing is conducted using the system application and the developed model, checking wether it is according to the user's requirements (Newman and Sproull, 1981; David and Adams, 1998; Giloi, 1999; Connolly and Begg, 2002; Ramez et al., 2000; Date, 1990; Pressman, 2001).

\section{Research Plan (Research Plan Schedule)}

\section{Step 1: Creating the Design Mode}

The first step is to perform a literature study, data and information searching, from books or the internet, in order to get the latest information on the development of this method and the reasearch model and also to study the existing model. Then searching for actual information and facts from other institution. The data collected (Giloi, 1999) empirically is used as a means to develop the model and the relationships of the required files, in terms of the advantages of using Bezier algorithm and B-Spline.

\section{Step 2: Model Implemetation}

The model obtained from the survey is then implemented in a software that can be used by the institution or department in the areas surveyed. In addition to the software, a guide is also developed for users to facilitate the use of software better.

From the use of the software, the evaluation of the implementation of the model for further refinement. Evaluation of the implementation is done by using a questionnaire to obtain feedback.

\section{Step 3: Model Verification}

Verification of the early model equations are used and the results of a survey on the use of the software is developed. In order to study the design, the influence of the system software is analyzed.

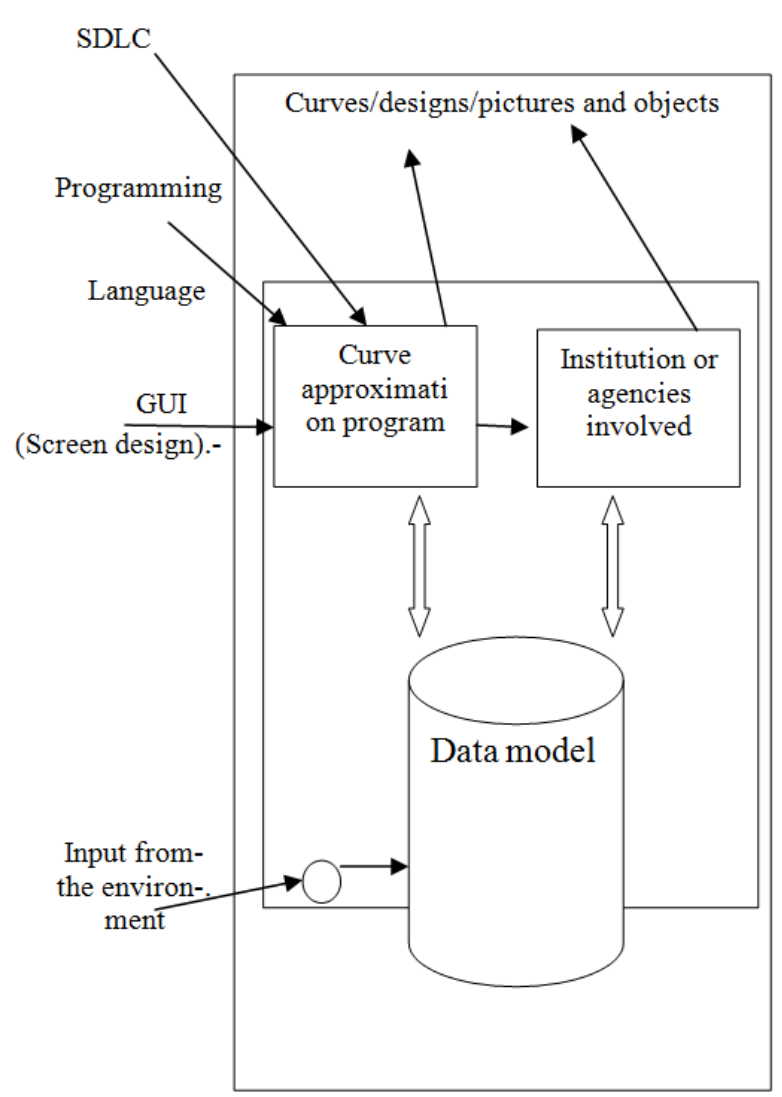

Fig. 1. Thinking of this research

\section{The Study Should Refer to ROAD MAP/RIP UBINUS}

Fokus and Road Map/RIP Specialization in SoftComputing Research Department of Information Bina Nusantara University

Soft-Computing Specialization of Department of Information Binus University directs graduates as an application developer, especially in the field of information systems Graphics and Computing.

It includes the possibility of researc in other domain of Soft-Computing.

This graphics system is a problem in the industry for the manufacture of objects such as numbers, letters, pictures and objects according to the user's requirements.

The research has been carried out as a student project with the guidance of the Chairman of the Project Djunaidy Santoso Dipl.Ing M.Kom.

This field, need to be developed further, because it serve as a point where it is widely needed by industries, ecause the product resulted from using the algorithm will be beneficial (David and Adams, 1998).

In making this design there is the need of System design and also there is a requirement of a database system (Giloi, 1999) that is reliable and convenient method of designing screens for user (user) (Ramez et al., 2000), so that the 
output obtained can be fast, accurate and as needed, because the software is developed with easy to understand menus and hence easy to digest (Ramez et al., 2000). Therefore helping the decision making by the users.

The development method is based on the system development life cycle, such that it will make it easier for the developer to develop and maintain the system.

The research in this field is according to the direction of the research road map at the School of Computer Science, Bina Nusantara University (refer to ROAD MAP of Bina Nusantara University).

\section{Results and Discussion}

\section{Testing and Results}

The result obtained by running the above program under $\mathrm{C}++$ with Open GL in the computer that will be used to test the correctness of the Bezier and B-Spline algorithm through Display monitor, not a printer, as the smoothness of the curve is better shown on screen rather than on paper.

CD ROM is included. (When necessary, the CD can be given, as the code of this program is not included in this study/article.

\section{Aknowledgement}

The results that have been achieved as acknowledgement: Some of the observations, there are some things that need to be addressed:

- The Her006Dite interpolation method there is still less smooth curve

- Bezier methods are the result of the final curve and polygon only, which is not as desired dynamic

The increase in the graphic/numbers/letters/images. necessary to use another method, B-Spline, B-Spline because there are a number of his order K, i.e., to select the desired curve. The simulation program in the making of this application there are still some shortcomings that need to be further developed, namely the need to develop a module that can enter the order $\mathrm{k}$ and the data objects dynamically in accordance curve desired. The results ever achieved for research for comparison between the curves approximating the curve interpolation example: Hermite curve interpolation, not only discussed as a comparative study with the curve approximation.

That all the points will study the statistics of the curve traversed either from the starting point to the end point, the only difference approximation with the Bezier curve and B-Spline is only the starting point and end point just passed. The point of the midpoint between the starting point and end point only averaged only (on Lagrange Interpolation curve, Newton and Hermite and others in the area at the point of starting point and ending point area strain curves are very steep). Another characteristic feature on Bezier curves and B-spline curve that is when desired curve becomes smooth tangent direction must be made sustainable and turning points of maximum and minimum turning points need to be considered very significant.

That needs to be Investigated First Bezier Functions:

By taking the point $\mathrm{Po}=(2 / 6)$ :

$$
\begin{aligned}
& \mathrm{P} 1=(4 / 12) \\
& \mathrm{P}_{2}=(7 / 3) ; \mathrm{P}_{3}=(9 / 10)
\end{aligned}
$$

Mean $\mathrm{n}=3$; after the binomial coefficients are calculated, the calculated blending function obtained:

$\mathrm{b} 0,3(\mathrm{t})=(1-\mathrm{t}) 3$

$\mathrm{b} 1,3(\mathrm{t})=3 * \mathrm{t} *(1-\mathrm{t}) 2$

$\mathrm{b} 2,3(\mathrm{t})=3 * \mathrm{t} 2(1-\mathrm{t})$

b3, $3(\mathrm{t})=\mathrm{t} 3$

Obtained after blending functions, the new calculated Bezier polynomial function P (t) (David and Adams, 1998).

Then obtained:

$$
\begin{array}{ll}
\text { Po }(\mathrm{t}=0) & =(2 / 6) \\
\text { P1 }(\mathrm{t}=0.15) & =(2.9586 / 7.7902) \\
\text { P2 }(0.35) & =(4386 / 8125) \\
\text { P3 }(\mathrm{t}=0.5 & =(5575 / 7625) \\
\text { P4 }(\mathrm{t}=0.65) & =(6625 / 7208)) \\
\text { P5 }(\mathrm{t}=0.85) & =(8.0374 / 7.8242) \\
\text { P6 }(\mathrm{t}=1) & =(9 / 10)
\end{array}
$$

\section{The Second Study B-Spline Functions}

With the same point eperti research Bezier functions: First calculate the value knotvektor and incorporated into the B-spline blending function obtained polynom Bspline functions are:

With order $\mathrm{k}=2$ obtained:

$$
\begin{aligned}
& \text { Po }(\mathrm{t}=0)=(2 / 6) \\
& \text { P1 }(\mathrm{t}=0.5)=(3 / 9) \\
& \text { P2 }(1)=(4 / 12) \\
& \text { P3 }(\mathrm{t}=1.5)=(5.5 / 7.5) \\
& \text { P4 }(\mathrm{t}=2.0)=(7 / 3)) \\
& \text { P5(t=2.5) }=(8.0 / 6.5) \\
& \text { P6(t=3.0) }=(9 / 10)
\end{aligned}
$$

With order $\mathrm{k}=3$ obtained:

$$
\begin{aligned}
& \text { Po }(\mathrm{t}=0)=(2 / 6) \\
& \text { P1 }(\mathrm{t}=0.5)=(3,875 / 9,375) \\
& \text { P2 }(\mathrm{t}=1)=(5.5 / 7.5) \\
& \text { P3 }(\mathrm{t}=1.5)=(7125 / 5875)) \\
& \text { P4 }(\mathrm{t}=2.0)=(9 / 10)
\end{aligned}
$$

With order $\mathrm{k}=4$ obtained: 


$$
\begin{array}{ll}
\mathrm{Po}(\mathrm{t}=0) & =(2 / 6) \\
\mathrm{P}_{1(\mathrm{t}=0.5)}=(5.5 / 7.625) & =(9 / 10) \\
\mathrm{P}_{2(\mathrm{t}=1)} &
\end{array}
$$

\section{Results and Discussion about Previous Research}

0(Filing and Quoting) from the calculation of Bezier function:

$$
\begin{array}{ll}
\text { Po }(\mathrm{t}=0) & =(2 / 6) \\
\text { P1 }(\mathrm{t}=0.15) & =(2.9586 / 7.7902) \\
\text { P2 }(0.35) & =(4386 / 8125) \\
\text { P3 }(\mathrm{t}=0.5 & =(5575 / 7625) \\
\text { P4 }(\mathrm{t}=0.65) & =(6625 / 7208)) \\
\text { P5 }(\mathrm{t}=0.85) & =(8.0374 / 7.8242) \\
\text { P6 }(\mathrm{t}=1) & =(9 / 10)
\end{array}
$$

\section{Discussion for Bezier}

The first curve yield curve polygon and the second produces the same curve as the last curve of the Bpline, the point P0, P3 and P6 together with B-Spline curve of order $\mathrm{k}=4$ (always order the last $\mathrm{k}$ equals the number of points).

And the results of B-Spline function calculation by order $\mathrm{k}=2$ :

$$
\begin{aligned}
& \text { Po }(\mathrm{t}=0) \quad=(2 / 6) \\
& \text { P1 }(\mathrm{t}=0.5)=(3 / 9) \\
& \text { P2 }(1) \quad=(4 / 12) \\
& \text { P3 }(\mathrm{t}=1.5)=(5.5 / 7.5) \\
& \text { P4 }(\mathrm{t}=2.0)=(7 / 3)) \\
& \text { P5 }(\mathrm{t}=2.5)=(8.0 / 6.5) \\
& \text { P6 }(\mathrm{t}=3.0)=(9 / 10) \\
& \quad \text { Order } \mathrm{k}=3: \\
& \text { Po }(\mathrm{t}=0)=(2 / 6) \\
& \text { P1 }(\mathrm{t}=0.5)=(3,875 / 9,375) \\
& \text { P2 }(\mathrm{t}=1)=(5.5 / 7.5) \\
& \text { P3 }(\mathrm{t}=1.5)=(7125 / 5875)) \\
& \text { P4 }(\mathrm{t}=2.0)=(9 / 10) \\
& \quad \text { Order } \mathrm{k}=4 \text { didapat: } \\
& \mathrm{P}_{\mathrm{o}(\mathrm{t}=0)}=(2 / 6) \\
& \mathrm{P}_{1(\mathrm{t}=0.5)}=(5.5 / 7.625) \\
& \mathrm{P}_{2(\mathrm{t}=1)}=(9 / 10)(\text { David and Adams, 1998) }
\end{aligned}
$$

\section{Discussion on B-Spline}

That the order is always the case $\mathrm{k}=2$ polygon curve. Last B-Spline curves congruent with Bezier curves. Of the two algorithms above, a smooth curve can be obtained on making the numbers $0-9$, the letters A-Z (a-z) and image map of a region border territory of a State as well as the manufacture of electronic drawings and images image analysis results in the field of Medicine, When the second algorithm is studied to develop the blending function then there will be better results. Preliminary study ever conducted on with the use of data statistics by using Bezier method, the data was processed statistical data so that there are two curves of the form of a Polygon and the other end of the same curve with B-Spline method.

\section{Conclusion}

From the test result, a conclusion can be drawn as follows: That the program is sufficient, the data model is drwan according to the algorithms and the result is that the curves are better (more smooth) as required by the user.

\section{Suggestion for Further Research}

The reuirement to evaluate the hardware, especially the monitor with, high resolution and adequate CPU requirements, as the data can be very large in size and a comparison of the algorithm with other curves. Menu displays can be either stactic or dynamic.

\section{Funding Information}

The authors have no support or funding to report.

\section{Ethics}

This article is original and contains unpublished material. The corresponding author confirms that all of the other authors have read and approved the manuscript and no ethical issues involved.

\section{References}

Connolly, T. and C. Begg, 2002. Database Systems. 1st Edn., Addison Wesley Longman, Inc, USA.

Date, C.J., 1990. An Introduction to Database System. 1st Edn., West Publishing Company, St. Paul, ISBN-10: 0314667717, pp: 820.

David, F.R. and J.A. Adams, 1998. Mathematical Elements for Computer Graphics. 2nd Edn., McGraw-Hill College, New York, ISBN-10: 0070535299, pp: 611.

Giloi, W.K., 1999. Interactive Computer Graphics. 1st Edn., Prentice Hall, Inc., Englewood Cliffs, New Jersey.

Newman, W.M. and R.F. Sproull, 1981. Principles of Interactive Computer Graphics. 2nd Edn., McgrawHill College, ISBN-10: 0070463387, pp: 541.

Pressman, R.S., 2001. Software Engineering: A Practitioner's Approach. 5th Edn., MC Graw-Hill, New York.

Ramez, E., D. Navathe and B. Shamkant, 2000. Fundamentals of Database Systems. 1st Edn., Addison Wesley Publishing Company, Inc, United States of America. 